\title{
Disagreement or Badmouthing? The Role of Expressive Discourse in Politics
}

\author{
Michael Hannon
}

\section{Introduction}

Is Barack Obama the founder of ISIS? Was he born in the United States? Does the United Kingdom send $£ 350$ million to the European Union each week? Would the world be safer if everyone owned a gun? Is global warming going to be catastrophic if we don't take immediate action?

These questions provoke strong disagreement. So do plenty of others. Political opponents cannot agree on matters concerning the economy, foreign affairs, education, energy, health care, the environment, privatization, and immigration. In the United States, nearly half of all Republicans and Democrats say they "almost never" agree with the other party's positions (Doherty et al. 2016). When it comes to politics, there seems to be no end to the number of issues over which people disagree.

Political disagreement is often a good thing for a healthy democracy. We expect values and preferences to differ in a pluralistic society, and reasonable citizens understand that people of good will can disagree about moral and political issues (Rawls 1993). However, partisan disagreements have spread beyond political values and even include disputes about obvious matters of fact (Sinnott-Armstrong 2018; Bartels 2002). In the United States, for example, Democrats and Republicans disagree about whether the GDP has gone up or down, whether unemployment rates are better or worse, how many immigrants entered the United States illegally, and many other topics. Consider the issue of climate change. The extent and causes of climate change are scientific questions that should be settled independently of one's 
political beliefs. Yet politics seems to drive our beliefs about the facts instead of the facts driving policy.

This is a significant problem for democratic politics. If partisanship is shaping our perceptions of reality, then democratic decision-making becomes incredibly difficult. Without agreement on the facts, voters will be unable to hold representatives accountable, to productively deliberate with others, and to find political compromise.

But is political disagreement as extensive and deep as many have claimed? In this paper I will argue that many apparent political disagreements are not genuine disagreements. I draw on three sources of evidence to justify this claim, described below.

First, new evidence suggests that voters are increasingly polarized in terms of their attitudes towards each other, even though there has been comparatively little polarization on the issues. As Lilliana Mason (2018) puts it, politics is increasingly characterized by "uncivil agreement”. Voters have grown more partisan, angry, and biased against their political opponents, but these reactions have almost nothing to do with one's opinions about the issues. We are simply behaving as if we disagree.

Second, survey data tends to exaggerate the level of disagreement in politics. When surveyed about political issues, people often deliberately misreport their beliefs as a way to express their attitudes. This is called "expressive responding". People engage in this behaviour for one of two reasons: either partisans know the truth but prefer to "cheerlead" when there is nothing to gain from accuracy, or they are ignorant on the issue and they offer a congenial answer as their best guess. Either way, survey responses are not entirely sincere. Thus, we should not interpret these responses as evidence that partisans are unable to agree. 
Third, voters often claim to have policy convictions when, in fact, they do not have robust political beliefs at all. Here I follow the democratic 'realists' who argue that people vote largely on the basis of partisan loyalties, not sincere policy preferences (Achen and Bartels 2016). Although many citizens will describe themselves as "liberal" or "conservative", they actually lack stable beliefs fitting these ideological self-descriptions. What seems like deep political disagreement is actually superficial and inauthentic.

All this suggests that political disagreement is neither as deep nor as extensive as many have thought. What follows from this fact?

There are several significant implications that I will explore in the second half of this paper. For example, I will argue that insincere disagreement explains why debates often go so poorly, why people seem to hold blatantly contradictory beliefs, and why it is often so difficult to correct false beliefs. I will also discuss some positive and negative implications of the idea that political disagreement is often illusory. On the positive side, I will argue that political surveys tend to overstate the level of political misinformation, that motivated reasoning is not distorting our perceptions of reality as often as many scholars claim, and that there is less disagreement over the facts than survey data suggest. This is good news. The bad news is that voters are not supporting policies based on their actual content, we cannot decrease polarization by reasoned debate, and people are not genuinely interested in engaging with their political opponents.

\section{Division Without Disagreement}

According to a common view of politics, voters tend to choose the political party that best matches their own interests and issue positions. This is the "folk theory of democracy" (Achen and Bartels 2016). Imagine a voter who thinks that corporate and individual tax cuts 
will help create a booming economy, and that there is a critical need for an immigration policy that secures the border and limits migration. Such a person is likely to vote Republican, according to the folk theory, because the Republican Party will better represent this voter's interests and values. The folk theory predicts that party affiliation is strongly linked to issue positions, since voters will choose to support whichever party best reflects their political preferences.

The folk theory of democracy is intuitive, rational, and widely accepted. It is also largely incorrect.

In Uncivil Agreement, Lilliana Mason argues that many citizens do not base their voting decisions primarily on the proximity of the policy positions of parties to the voters' own positions. Rather, their decisions are based on social identity. A 'social identity' involves

a subjective sense of belonging to a group that is internalized to varying degrees, resulting in individual differences in identity strength, a desire to positively distinguish the group from others, and the development of ingroup bias. (Mason et al. 2015: 3)

Social identity theory is a powerful foundation to study partisanship and political behavior. On this model, the strength of a person's partisanship can derive from a number of influences that have nothing to do with political issues; in particular, partisan strength seems to be rooted in social group memberships, social networks, and cultural identity (Campbell et al. 1960; Mutz 2002). These influences may increase the strength of partisanship without any 
corresponding increase in the extremity of issue positions (Mason 2018 and Iyengar et al. 2012). ${ }^{1}$

This captures the current state of American politics. On the one hand, Democrats and Republicans are increasingly polarized in the sense that they dislike each other more than ever, ascribe negative traits to members of the other side, and even claim that they would be upset if their children married someone from the other party (Iyengar et al. 2012). On the other hand, there has been almost no increase in the extremity of issue positions in the mass public (Iyengar et al. 2019; Iyengar et al. 2012; and Fiorina and Abrams 2008). ${ }^{2}$ To borrow some terminology from Iyengar and his colleagues (2012), there has been an increase in "affective polarization" without a corresponding increase in "issue-based polarization". Affective polarization is characterized by increased partisan strength, partisan bias, political activism, and anger, while issue-based polarization occurs when citizens move from moderate issue positions to more extreme ones. Although there has been increased issuebased polarization at the level of political elites (e.g., members of Congress), there is little evidence that ordinary citizens increasingly disagree on the issues. ${ }^{3}$ Rather, they simple dislike, even loathe, each other more.

This suggests that partisans have grown increasingly distant and hostile toward each other even though their policy disagreements are not profound. In fact, many Democrats and Republicans do not differ that much on matters of public policy. Rather, they continue to hold relatively inconsistent policy attitudes, and have done so for decades (Converse 1964; Achen

\footnotetext{
'Extremity' refers to a person's movement from a moderate policy position to a less moderate one, as well as the strength with which they hold their view (Mason 2013: 142).

-Abramowitz and Saunders (2008) contest this claim. See Fiorina et al. (2008) for a reply.

According to the Pew Research Center (2014), the partisan gap has increased on some issues over the past few decades. For example, when asked whether "government regulation of business usually does more harm than good", the partisan gap has more than doubled from 1994 to 2004. I will not deny that there is evidence of a partisan gap on some issues. However, these differences may not reflect changes in genuine beliefs (as I'll argue in section 3). Rather, these changes reflect changes in the social returns of cheerleading for one's political team. This fits nicely with the recent empirical work showing there has been a large increase in affective polarization. As the strength of partisanship increases, people become more motivated to engage in cheerleading behaviour (Bullock et al. 2015). This also explains why the partisan "gap" is most pronounced during campaign seasons, since elections may make more salient the need to support one's party (Iyengar et al. 2012).
} 
and Bartels 2016; Kinder and Kalmoe 2017; Mason 2018). For example, Mason measured Americans' preferences on six major issues - immigration, the Affordable Care Act, abortion, same-sex marriage, gun control, and the relative importance of reducing the deficit or unemployment - and found that identifying as a "liberal" or "conservative" only explained a small part of their issue positions. It seems that people are polarized by labels such as "liberal" and "conservative" (and what they imagine their opponents to be like) more than they are by actual disagreements over topics like immigration, abortion, and taxes. As a result, Americans have become angrier with their political opponents while not disagreeing with them on many issues.

Why, then, do liberals and conservatives hate each other so much? If these feelings are not rooted in policy disagreements, what are they based on?

The proliferation of partisan news outlets and high-choice media environment is frequently blamed for the current polarized environment (Lelkes et al. 2017). But this explanation might get things backwards: those who are most polarized are also more motivated to watch partisan news; thus, partisan news may not be the cause of affective polarization. ${ }^{4}$ It is also common to blame the Internet and social media for echo chambers, filter bubbles, and polarization; but the relationship between Internet access and affective polarization has also been contested (Boxell et al. 2017).

Whatever the exact causes of polarization might be, it is widely acknowledged that the strengthening of partisan identities has little to do with the issues and almost everything to do with group loyalty and party identity. Once we identify with a particular party, we highly motivated to protect and advance our group's status. This is identity politics at its worst.

\footnotetext{
"See Arceneaux and Johnson (2013) and Prior (2013). In contrast, Levendusky (2013) finds that exposure to partisan news makes those with extreme attitudes even more extreme. It seems plausible that partisan media consumption can be part of a feedback loop that increases affective polarization. That is, affective polarization gets started via other channels, but media consumption and online "echo chambers" exacerbate it.
} 
Democrats and Republicans tend to hate each other but this hatred has almost nothing to do with their opinions on the issues. They dislike the other team simply because they are the other team. As a consequence, we have an electorate that is increasingly divided and raring to fight, yet there is a lack of any substantive policy reasons to do so. Although Democrats and Republicans conceive of themselves as disagreeing over substantive issues like tax policy, health care, and government regulation, the political conflict in America today is not really about these things. It is rather about team identification and winning for its own sake. I will return to this topic in section 4.

\section{Political Expressivism}

As the previous section illustrates, people often behave as though they disagree even when there isn't much disagreement. This is because partisanship can affect our attitudes towards others without necessarily affecting our beliefs about the relevant issues.

Partisanship can also lead people to say things that create the appearance of disagreement. In particular, people may deliberately misreport their political beliefs as a way to express their attitudes. This is called "expressive responding" or "cheerleading” (Bullock et al. 2015).

Sometimes it is obvious that partisans are just cheerleading. Consider what Trump supporters say when asked to compare photos of his 2017 inauguration crowd and Obama's in 2009. In a survey of almost 700 American adults, participants were shown a crowd picture from each inauguration and asked a very simple question: "Which photo has more people?" Although

only one answer is clearly correct, Trump supporters were seven times more likely (compared to Clinton voters) to say that the half-empty photo of Trump's inauguration had more people. Trump supporters with college degrees were the most likely to answer incorrectly: $26 \%$ of them gave the clearly wrong answer. 
Do these people really believe there are more people in the obviously half-empty photo? It would be mistaken to interpret their responses in this way. Instead, some Trump supporters clearly decided to express their support for Trump rather than to answer the question factually. As Elizabeth Anderson (in this volume) puts it, "it is a way of showing those smug liberal academics [who were conducting the survey] that Trump voters will stand their ground in repudiating insults toward their group." They were not making a factual claim; their answer was expressive.

Expressive responding may also explain why approximately one in seven Americans will say that Obama is "the antichrist". 5 Do these people really believe this? Maybe some do. But a likely scenario is that such reports often reflect partisan cheerleading rather than genuine belief.

How often do people misreport their beliefs?

Probably a lot. A seminal finding of new research in political behaviour is that what seems like factual disagreement is often just partisan cheerleading or badmouthing. For example, John Bullock and colleagues (2015) find that partisans tend to give more accurate (and less partisan) responses to politically charged questions when offered monetary incentives to do so. As a result, the gap between Democrats and Republicans in response to factual questions sharply decreases. More specifically, small payments for correct answers reduced partisan divergence by at least $60 \%$. They reduce by $80-100 \%$ when participants are paid both for correct responses and a smaller amount for admitting they do not know the correct response.

The dramatic effects of a small incentive for accuracy_or a smaller incentive to admit that one doesn't know the answer-suggests that survey responses often reflect "the expressive value of making statements that portray one's party in a favorable light" (Bullock et al. 2015: 
521). As Gary Langer, former chief pollster for ABC News, aptly remarks: "some people

who strongly oppose a person or proposition will take virtually any opportunity to express

that antipathy...not to express their 'belief,' in its conventional meaning, but rather to throw verbal stones."

This finding is supported by multiple independent studies. ${ }^{6}$ Markus Prior and colleagues (2015) asked members of the public about objective economic conditions, such as whether the level of employment has gotten better or worse. They found that supporters of the current president's party tended to report more positive economic conditions than its opponents, but this tendency was significantly reduced when survey-takers were financially motivated to answer factual questions accurately. ${ }^{7}$

If these survey responses reflected actual beliefs, then paying partisans to answer correctly should not affect their responses. Yet it does. The observed gaps between Democrats and Republicans are substantially reduced with relatively small payments. This suggests that partisans "do not hold starkly different beliefs about many important facts" (Bullock et al. 2015: 522). Further, it indicates that partisans have the capacity to acknowledge inconvenient truths and are willing to report them when motivated to do so. Without adequate incentives, however, the motivation to give an answer that supports one's political party may outweigh

\footnotetext{
'See also the studies by Huber and Yair (2018) and Khanna and Sood (2018). Peterson and Iyengar (forthcoming) found that partisan cheerleading inflates divides in factual information, but only modestly. This is consistent with my general hypothesis that the extent and depth of political disagreements is likely overstated; I do not claim that political disagreements are entirely or primarily insincere. Moreover, this study may underestimate the extent of cheerleading by failing to adequately incentivize participants in the treatment condition. As the authors note, their study used a smaller financial incentive than the higher rewards in previous studies; further, this study assessed responses to issues that were especially divisive in nature. As a result, incentives for accuracy may have actually provided people with an opportunity for more powerful expression. When someone wants to express strong support for a politician or political party, they may do so by spurning the opportunity to receive monetary compensation for reporting their true belief. Work by Philip Tetlock (2003) suggests that "sacred values" are usually held to be incommensurable with - and tainted by - financial reward. Thus, if people count support for a politician or party as a sacred value, they will likely reject the opportunity for financial reward in exchange for accuracy.

- An alternative explanation, suggested by Neil Levy and Robert Ross, is that respondents are simply pretending to hold certain beliefs in order to get the reward. On this interpretation, these studies show that people are aware of the mainstream view and will claim to believe it when incentivized to do so. While I agree this is an important concern, it does not obviously apply to the studies I am discussing. In the cases of Prior et al. (2015) and Bullock et al. (2015), participants were provided with a mix of questions that favoured both Republicans and Democrats, and where there was no obvious "mainstream view" regarding the answers (e.g., "Is the economy doing better or worse?", "Has unemployment increased or decreased?", etc.).
} 
the motivation to give an accurate response. This can be for one of two reasons: either survey-takers have accurate but uncongenial information and they prefer to give congenial but inaccurate answers, or they are ignorant on the issue and they offer a congenial answer as their best guess. ${ }^{8}$ Either way, survey responses are not revealing misinformation or political disagreement.

This finding is incredibly significant. Public opinion polls are consistently showing that partisans are unable to agree on the facts. For example, Republicans are more likely than Democrats to say that the deficit rose during the Clinton administration; Democrats are more likely than Republicans to say that inflation rose under Reagan (Bartels 2002: 519). Similar patterns exist when they are asked factual questions about healthcare (Nyhan and Reifler 2010), foreign policy (Jacobson 2010), and social services (Jerit and Barabas 2012), among other issues. When people are surveyed about factual issues, they are more likely to report having beliefs that are favourable to their existing beliefs and attachments than beliefs that are unfavourable. These patterns are ordinarily taken as evidence that partisanship affects factual beliefs about politics. ${ }^{9}$ Democrats and Republicans are allegedly seeing "separate realities" (Kull et al. 2004).

An alternative explanation is that such patterns merely reflect a desire to praise one party or condemn another. Thus, instead of assuming that the public is misinformed, we should assume that the public is misinforming us. In doing so, these survey responses mask shared, bipartisan beliefs about factual matters.

This is likely not just an American phenomenon. Nearly half of the British public still claim to believe that the U.K. sends $£ 350 \mathrm{~m}$ to the E.U. each week, despite persistent attempts to

\footnotetext{
${ }^{8}$ See Bullock et al. (2015) and Prior et al. (2015) for evidence of the first explanation, and Luskin et al. (2013) for evidence of the second explanation.

- Those who take survey responses at face value include Campbell et al. (1960), Kull et al. (2004), Jerit and Barabas (2012), Shapiro and Bloch-Elkon (2008), and Jacobson (2010).
} 
debunk this myth. ${ }^{10}$ A new study by the Policy Institute at King's College London found that $42 \%$ of people who had heard the claim still believe it is true, whilst only $36 \%$ thought it was false and $22 \%$ were unsure. According to this study, conservative voters and Brexit voters are particularly susceptible to the misinformation, with $54 \%$ and $61 \%$ of each buying the claim. If we take these figures at face value, we are led to conclude that nearly half of the British public continues to be misinformed about the issue because they continue to believe that this claim is true. This is precisely how Professor Bobby Duffy, director of the policy institute that carried out this research, interprets these results. In an interview with The Independent, he says, "These misperceptions raise important questions about the basis of our decisionmaking... the fact that different groups see the same realities so differently shows how divided we are."

Are these people seeing the same reality differently? As I've suggested, we should be wary of taking answers to factual questions with partisan implications at face value, since they are often contaminated by the motivation to root for one's team. People believe one answer, but they give a different answer to support their party. It represents nothing more than partisan bad-mouthing and the joy of cheerleading.

\section{Voters Without Beliefs}

So far I have discussed two reasons why the extent and depth of political disagreement may be overstated. First, increasing levels of polarization tend to reflect our attitudes towards our political opponents but not our policy preferences or issue positions. Second, the partisan gap revealed by survey data largely reflects team cheerleading and cheap talk, not genuinely held political beliefs.

${ }^{10} \mathrm{https}: / / \mathrm{www} \cdot \mathrm{kcl}$.ac.uk/policy-institute/research-analysis/the-publics-brexit-misperceptions. 
I now want to consider a third—and perhaps more radical—reason to think that political disagreement is often illusory. The idea, briefly put, is that voters typically do not have many stable political beliefs. Indeed, many of their political "beliefs" may not be beliefs at all. Politics today is largely identity politics: citizens vote primarily on the basis of partisan loyalties that are grounded in social identity, not sincere policy preferences. ${ }^{11}$

Christopher Achen and Larry Bartels defend this view, which they call 'political realism'. They describe the view as follows:

voters choose political parties, first and foremost, in order to align themselves with the appropriate coalition of social groups. Most citizens support a party not because they have carefully calculated that its policy positions are closest to their own, but rather because 'their kind' of person belongs to that party. (Achen and Bartels 2016: 307)

The true psychological basis for voting behavior, they claim, is not individual political preferences but group identity. People do not first identify the issues they care about and then align themselves with the political party that best reflects these preferences. Rather, people first identify themselves with a group and then vote according to this group allegiance.

For realists, politics resembles sports and voters are like sports fans. Consider the Toronto Raptors (a basketball team) and their fans. People from Toronto — like myself — become

\footnotetext{
"This claim differs from the explanations offered in the previous two sections. In section 2, I argued that people largely agree on the issues even though they dislike each other. In section 3, I argued that partisan cheerleading masks shared beliefs. Now, I am exploring the idea that partisans often lack stable beliefs about political issues; they are what Mason (2018) calls "ideologues without issues". As a result, there is some tension between the claims defended in the previous two sections and the claim I am now exploring. In particular, sections 2 and 3 imply that political opponents $d o$ have shared beliefs about many issues, whereas I am now suggesting that partisans may not have beliefs on many political issues. Let me provide two quick replies to this worry. First, we needn't view these explanations as all or nothing. People like Mason may be right that when citizens do have beliefs about political issues, these beliefs often overlap with the views of their opponents; but it may also be true that many apparent political beliefs are not genuine beliefs. It simply depends on which beliefs we're investigating. Second, these explanations needn't be compatible for my argument to go through. I may be interpreted as offering a variety of plausible explanations for illusory political disagreement, but it is not necessary for my conclusion - that many apparent political disagreements are not genuine disagreements - that these explanations are compatible with each other.
} 
Raptors fans because we are from Toronto. We do not first form strong opinions about basketball and then examine the teams on offer and finally select a team to support based on how well that team realizes our pre-existing preferences or values. ${ }^{12}$ Rather, we cheer for the Raptors because that team is connected to our demographic identity. On the realist view, political affiliation is psychologically equivalent to sports team loyalty (at least for most citizens). Just as one's loyalty to a particular basketball team is not a reflection of one's preexisting ideological commitments about basketball, one's political affiliation is also not a reflection of one's political, moral, or otherwise ideological commitments. Rather, the typical voter becomes attached to a political "team" largely due to accidental historical circumstances. ${ }^{13}$ They are simply born into it, just as children typically inherit the religious affiliations of their parents. ${ }^{14}$

This point calls for two important qualifications. First, some voters may initially get their political allegiances by enculturation, but this doesn't preclude them from genuinely coming to believe some (or a lot) of the things their political party stands for. This may occur through a process of reflection on the attitudes they inherited from their community. Second, political realism is implausible as an account of political elites and people who devote their careers to politics. These people surely have genuine beliefs about the issues. My point, however, is that many people are not like this. According to a vast range of empirical research, the typical voter in the U.S. today resembles a sports fan. ${ }^{15}$

\footnotetext{
II borrow this type of example from Brennan (in this volume). Somin (2013: 78-9) also likens voting behavior to that of sports fans.

"Brennan (2017; this volume), Achen and Bartels (2016: 213-266), and Campbell et al. (1960) all defend this claim.

"This is substantiated by a vast amount of empirical work. See Greenstein (1965), Jennings and Niemi (1981), and Sears (1983).

is The analogy with sports fans is not perfect: there seem to be important meta-cognitive differences between sports fans and politically partisan individuals. In particular, sports fans are likely aware of the fact that many of their beliefs reports are just instances of expressive responding (e.g. "Manchester is the best team ever!") and that they pick what teams they support on the basis of fairly arbitrary factors (e.g. upbringing). Put differently, sports fans are likely aware that their attitudes aren't full beliefs. In contrast, in the context of politics, even if people are engaging in expressive responding there might be many cases in which they are not meta-cognitively aware of the fact that they are responding expressively. Unlike sports fans, many voters might not believe they
} 
Admittedly, many citizens will describe themselves as "conservative" or "liberal". But most people actually lack stable beliefs fitting these ideological self-descriptions. They are not deeply committed to their proclaimed ideologies. As Jason Brennan (in this volume) puts it,

Their beliefs, if we can even call them that, do not reflect real commitments about the good or just, or about how the world works. Instead, expressing political "beliefs" is largely equivalent to wearing sports team colors; they are a form of conspicuous display intended to show membership in what are, for that voter, socially advantageous groups. For them, advocating a policy is like wearing the Patriots' blue and silver or waiving the Steelers' terrible towel ... Their commitment is no deeper than Patriots fans' commitments to blue, red, and silver; if the parties were to change policy platforms, most of their "ideological" voters would claim they agree with the changes, and some would claim they believed such views all along.

To illustrate, Brennan asks us to consider how many Republicans switched their "views" on numerous economic issues when Trump was elected. ${ }^{16}$ They went from pro-free trade to protectionist almost overnight, without batting an eye. This suggests that even apparently key issues like free trade are, at bottom, just proclamations intended to demonstrate group membership. ${ }^{17}$ Similarly, when Democrats say "I'm pro-regulation", they may not be expressing a belief about appropriate responses to market failure; rather, they are just expressing a commitment to seeing the Democrats win. The implicature is "Hurray, Democrats!" (Brennan in this volume).

support political issues on the basis of arbitrary factors like upbringing. Thanks to Robert Ross and Neil Levy for making this point, which deserves to be explored in more detail (elsewhere, alas).

${ }^{10} \mathrm{https}: / /$ www.vox.com/science-and-health/2017/11/17/16585982/psychology-memory-polls-trump "This doesn't mean that the average citizen has no firm beliefs about basic moral issues. Most people probably have a wide range of genuine ethical commitments relevant to their day-to-day lives, such as the morality of keeping promises or stealing (Haidt 2012). The point, as Brennan (in this volume) says, is that these basic moral principles "radically underdetermine politics", and that getting to any political policy from these basic moral principles will always require additional empirical claims and opinions about social scientific issues and matters of basic political knowledge. 
Indeed, people will support whatever policy or platform they think is backed by their party. Geoffrey Cohen's (2013) work provides a striking example of this. He ran a study in which participants were told about two welfare programs: a harsh (extremely stingy) welfare program and a lavish (extremely generous) one. When Democrats were told that their ingroup party supported the harsh policy, they approved of it. When Democrats were told that their party supported the lavish policy, they approved of that instead. The same thing happened with Republican participants. All that mattered was which party was said to support the program; it made little difference what the actual content of the policy was. ${ }^{18}$ Moreover, the participants were unaware of this bias. When asked to justify their decision, the participants felt they were responding to the program's objective merits and insisted that party considerations were irrelevant. Relatedly, studies have found that people are unable to justify political positions they claim to feel strongly about. For example, people who claim to believe deeply in cap and trade often have little idea about what these policies actually entail (Brennan in this volume; Fernbach et al. 2013). What looks like the expression of a genuine belief is just a proclamation intended to display partisan affiliation.

What does all this mean for political disagreement?

It means that when a typical Democrat or Republican expresses their "beliefs" about some political issue, we shouldn't necessarily regard this as evidence that they genuinely disagree with their opponents. Rather, this behavior may be symbolic, expressing loyalty to their political team and a desire to see that team win, without any deeper commitment to what that team stands for. Thus, many people cannot quite be said to "believe" in their party's ideology or platform; they only express commitment to it. Consequently, their ideological “disagreements" are superficial and inauthentic.

\footnotetext{
${ }^{18}$ One might suggest that this is the result of the following heuristic: voters know that a particular party shares their general ideological outlook, so they use this as a way to determine what they would think about other issues. However, Gabriel Lenz (2012) tested this hypothesis and found little support for it.
} 
You might insist that these states of mind still qualify as beliefs. Perhaps voters do sincerely believe, say, that government regulation is good, even if they are unable to say anything else about the issue. Similarly, in the case of expressive responses (see section 3), you could think that voters believe one thing and then, when promoted by financial incentives, they revise and update their beliefs. Along this line, Levy (MS) argues that people are often simply reconstructing their beliefs from moment to moment.

Perhaps there is a sense in which we can call these mental states "beliefs". Think of them as fragile beliefs. Whether or not fragile beliefs really are beliefs is a verbal dispute that I would prefer to avoid. My worry is that these "beliefs" would not be sufficiently robust to serve as a satisfactory basis for democratic theory. A much thicker notion of belief lies at the heart of liberal democratic theory. This is evident from the first page of Robert Dahl's classic book, Polyarchy. He writes, "a key characteristic of a democracy is the continued responsiveness of the government to the preferences of its citizens". But the aim of a liberal democracy is surely not to aggregate just any wishy-washy individual preferences into collective choice, nor to include those that are merely expressive proclamations. It is for a similar reason that political theorists worry about framing effects on political preferences, which seem to show that individuals do not have "real political preferences" (Kelly 2012: 21). As Bartels (2003: 49) writes, the beliefs of citizens "are not sufficiently complete and coherent to serve as a satisfactory starting point for democratic theory, at least as it is conventionally understood".

Liberal democratic theorists have assumed that people have definite preferences and that a democratic government must respond appropriately to those (real) preferences. This is why Philip Converse, in his foundational work on the nature of belief systems in mass publics, said that citizens "do not have meaningful beliefs" on many political issues (1964: 245). The instability of fragile "beliefs" (if we choose to call them that) would therefore still create 
significant problems for attempts to discern public preferences on political issues. Thus, the distinction between a thicker notion of belief and a thin sense of belief is not merely a theoretical nicety.

Further, contemporary philosophers of mind generally use the term "belief" to refer to the attitude we have when we regard something as true. As revealed by the literature on expressive responding, however, citizens who make factual claims do not actually regard the content of these assertions as true. Thus, expressive responses would not qualify as beliefs even according to the standard definition of "belief" in contemporary Anglophone philosophy.

To be clear, I am not saying that people never choose political parties on the basis of their beliefs or policy preferences. My claim is only that in a vast range of cases, the folk theory of democracy does not fit the general picture of political reasoning that emerges from decades of empirical research across multiple disciplines. This literature suggests that an adequate account of partisan identity must give a central role to social identity, tribal allegiances, and expressive discourse.

\section{Implications}

What are the implications of this research? Suppose I am right that there is less disagreement in politics than we have been led to believe. What follows?

In the remainder of this paper, I will argue that we can explain some puzzling aspects of contemporary political life by appealing to the hypothesis that political disagreements are often illusory and merely the reflection of identity-expressive discourse. In particular, I will argue that this hypothesis sheds light on the following issues: 
- why people seem to disagree despite access to unequivocal evidence;

- why attempts to correct false beliefs sometimes backfire;

- why political debates often go so poorly;

- why it can be difficult to correct mistaken beliefs;

- why disagreement often seems irresolvable;

- why people are unaware of the most basic facts about political issues on which they express opinions;

- why people often seem to hold blatantly contradictory beliefs;

- why people often do not read the news posts they share;

- why motivated reasoning sometimes a poor explanation for polarization and misinformation;

- why it is a mistake to classify many political disagreements as "deep disagreements".

Let's start with why people seem to disagree about well-established facts even when the evidence is unequivocal and easy to access. This behavior might seem illogical, but my account provides a straightforward explanation: people are simply making claims about factual issues to signal their allegiance to a particular ideological community. When a Republican says that Trump's inauguration photo has more people, they are not actually disagreeing with those who claim otherwise. They're just cheerleading. Relatedly, the use of factual claims for tribal signalling or identity-expression may explain why attempts to correct false beliefs sometimes appear to backfire (Nyhan and Reifler 2010). If factual corrections are interpreted as challenges to our "team," the correction will seem to "backfire" because people will reply by expressing their loyalty.

This also helps us understand why debates often go so poorly. According to an optimistic view, political disagreement is a good thing because it allows citizens to encounter diverse 
perspectives, consider the value of alternative points of view, and evaluate their opinions in light of counterarguments. For these reasons, theorists from Aristotle to Mill, Dewey, and Arendt extolled the benefits of deliberation and disagreement in politics. Why, then, do real life political disagreements swiftly devolve into heated partisan rancour? It is because these disputes are not generally treated as opportunities to exchange reasons or make arguments. Rather, they are opportunities for cheering and booing. Recall the analogy with sports. When fans cheer for their team, this is not an exercise in rational deliberation. They are just expressing loyalty to their team. If political disagreement is similarly tribal, then we should view partisan claims about immigration, health care, and the like in a similar light. They are not conclusions articulated on the basis of reasons, but rather proclamations akin to "Yay, team!" and "Boo, the other guys!" As such, political disputes are not aimed at rational resolutions. And when partisans $d o$ give reasons or arguments for their views, these are most likely the product of rationalization, confabulation, and post-hoc reasoning (Haidt 2012).

As the empirical evidence shows, political attitudes are often not the products of careful reasoning. Further, it might be true that they're not supposed to be. ${ }^{19}$ When people cheer for the L.A. Lakers or Toronto Raptors, this is not supposed to be an exercise in rational deliberation. It would be misguided to complain that a Raptor's fan's enthusiasm for his team does not reflect a sober appraisal of the team's recent performance. That would miss the point. If politics is also about expressing team loyalty, then complaining that someone's views on global warming are not grounded in the facts may also be off the mark. Their views on these issues are not articulated conclusions but expressive proclamations.

In reply, one might argue that even if politics isn't typically an exercise in rational deliberation, it ought to be. We should treat political disagreements as an opportunity to exchange reasons, consider the value of alternative perspectives, and evaluate our opinions in ${ }^{19}$ Bloom (2016: 236) makes this argument. 
light of counterarguments. So even if politics does resemble sports, it shouldn't. We can therefore criticize individual citizens for failing to meet this standard—or so the objection goes.

However, political views may share another common property with views about sports teams - they don't really matter. As Paul Bloom (2016: 237) observes,

If I have the wrong theory of how to make scrambled eggs, they will come out too dry; if I have the wrong everyday morality, I will hurt those I love. But suppose I think that the leader of the opposing party has sex with pigs, or has thoroughly botched the arms deal with Iran. Unless I'm a member of a tiny powerful community, my beliefs have no effect on the world. This is certainly true as well for my views about the flat tax, global warming, and evolution.

While this idea is not uncontroversial, it has many defenders. The idea is that voters are 'rationally ignorant' (Somin 2013; Bloom 2016; Brennan 2017). A failure to gather evidence, attend to data, and consider counterarguments in the political domain does not reflect stupidity, laziness, or irrationality. It reflects how many of us make sense of politics: we care more about team loyalty than the truth because, for us, politics is not really about truth (Bloom 2016: 237). This would explain why people are unaware of even the most basic facts about the issues, policies, and politicians that they express opinions about.

It would also explain why it is often so difficult to correct false beliefs (or "beliefs"). If our political claims are expressions of cheerleading, then providing partisans with correct information may do little to change their minds (Bullock and Lenz 2019). When our views are not based on the facts or aiming at truth, we should not expect them to be rationally 
revisable in light of the evidence or reasoned argumentation. ${ }^{20}$ This would also explain why disagreements often seem irresolvable: we cannot resolve issues when there is no genuine disagreement.

The tendency to signal allegiance by making claims about factual issues would also explain why people often seem to hold blatantly contradictory beliefs. David Dunning and Peter Enns (2014) surveyed roughly 500 Americans and found that over $25 \%$ of liberals (but only $6 \%$ of conservatives) endorsed both the statement "President Obama's policies have already created a strong revival in the economy" and "Statutes and regulations enacted by the previous Republican presidential administration have made a strong economic recovery impossible.” Both statements are pleasing to liberals and thus may induce cheerleading behavior, even though it is impossible for Obama to have already created a strong recovery that Republican policies have rendered impossible. Among conservatives, 27\% (compared to just $10 \%$ of liberals) agreed both that "President Obama's rhetorical skills are elegant but are insufficient to influence major international issues" and that "President Obama has not done enough to use his rhetorical skills to effect regime change in Iraq." This seems contradictory: if Obama's rhetorical skills are insufficient, why should he be criticized for not using them to influence the Iraqi government? Dunning and Enns explain these results by appealing to psychological bias. Alternatively, we may regard these contradictory claims as expressions of attitude rather than empirical assertions.

The idea that political disagreements are often superficial has a lot of explanatory power. Once we realize that political disagreement is often illusory and merely a reflection of identity-expressive discourse, we can make a lot more sense of our currently political context.

${ }^{20}$ I am not saying that arguments and evidence never resolve political disagreements; only that they are typically ineffective. 
Our tendency to engage in identity-expressive discourse would also explain why people do not often read the news posts they share. Just as the primary function of certain claims about factual issues is to signal allegiance, the primary function of the communicative act of newspost sharing may also be expressive (Lynch 2019).

\section{Additional Upshots}

If this argument is correct, it has several additional upshots.

First, it suggests that standard survey research methods are flawed. ${ }^{21}$ The bulk of survey research assumes that respondents provide truthful answers when asked questions. If this assumption were correct, then conventional survey methods would provide evidence of real and deeply held differences in assessments of political facts. But as the literature on expressive responding makes clear, these partisan gaps are often illusory. The appearance of factual disagreement in politics is, to some extent, an artifact of survey measurement. Admittedly, we do not know the precise extent to which voter "misinformation" and factual "disagreement" are merely a reflection of identity-expressive discourse. Nevertheless, the research I have surveyed strongly indicates that many alleged disagreements are not real disagreements, and that what seems like a misinformed public is not in fact so.

Second, the appeal to "motivated reasoning" is sometimes incorrect. This theory says that people who come across the same information will walk away with different beliefs about what the evidence supports, since partisanship leads us to process factual information in biased ways (Taber and Lodge 2006). This is by far the commonest explanation for why voters are misinformed and increasingly polarized. However, the theory of motivated reasoning presumes that the misinformation documented by survey researchers is an accurate

"Bullock et al. (2015) and Prior et al. (2015) make this point. 
reflection of what individuals believe. I have tried to throw this assumption into doubt. When Trump voters point to a half-empty inaugural photo and say it has more people than an obviously full photo, this is not the result of a cognitive processing error. Motivated reasoning has not led them to believe that which flies in the face of unambiguous photographic evidence. What looks like motivated reasoning is just political cheerleading. This also explains why political "misperceptions" are the most common among the most political engaged. It is commonly assumed that the most strongly partisan are also the most likely to be biased and engage in motivated reasoning. This may be true, but this explanation ignores the fact that the most strongly partisan are also the most likely to engage in cheerleading and other forms of expressive responding. Thus, the theory of motivated reasoning may often misdiagnose partisan cheerleading as biased cognitive processing.

This leads me to another point. It is commonly said that many political disagreements are “deep disagreements" (de Ridder in this volume; Aikin 2019; Kappel 2018; Lynch 2010). A deep disagreement occurs when two or more people not only disagree about the facts, but also disagree about how best to form beliefs about those facts. For example, two people may disagree about the causes and consequences of climate change because they have different underlying commitments about what counts as good evidence, how to weigh difference sources of evidence, who the experts are, and so forth. When the disputing parties have fundamentally different epistemic commitments, it will be difficult (if not impossible) to reach a rational resolution.

According to Klemens Kappel (2018), most societal disagreements are deep disagreements. This allegedly explains why political disagreements are so intractable. However, I have argued that many cases of political disagreement are not genuine disagreements; thus, they cannot be deep disagreements. While I do not dispute the claim that political disagreements 
may sometimes be "deep", many of them may not be. Instead of thinking of these as deep disagreements, we should instead think they are relatively shallow. This would also explain why these disputes are not rationally resolvable. As I argued above, political disputes are often not aimed at rational resolutions; they are just opportunities to root for one's team.

A final upshot concerns the theory of public reason liberalism. According to public reason liberals, people have a diverse range of moral, religious, and political views. Consequently, citizens deeply dispute the nature of the good, what is just or unjust, and also which institutions, policies, and practices best realize their normative goals. This gives rise to a well-known normative problem in political theory: how can a government impose uniform moral and political rules upon all citizens without treating them as unfree and unequal?

Public reason liberals claim that we must be able to base a justification for coercive moral and political rules on the underlying beliefs of reasonable citizens. According to Brennan (in this volume), however, this central idea of public reason liberalism rests on a mistake. If 'political realism' is correct, then citizens actually have few real stable political beliefs. But if they lack the right kind of political beliefs, there is no sense in which policies or rules can be justified in light of them. As Brennan puts it,

they [citizens] 'wear' their political beliefs the way they wear sports colors, but they are not genuinely committed to such beliefs. So, there is nothing there upon which to base public justification.

This is a problem for the public reason theorist. ${ }^{22}$ Public reason liberals say that we should not force coercive policies on citizens; policies must be publicly justified on the basis of reasons that all reasonable citizens could accept. This assumes that citizens can themselves

\footnotetext{
${ }^{22}$ See Ancell $(2019 \mathrm{a} ; 2019 \mathrm{~b})$ for more discussion of how recent empirical evidence on political reasoning generates obstacles for public reason theorists.
} 
recognize and accept moral and political rules in light of their own beliefs. But if people do not actually have the requisite beliefs, values, or commitments, then we cannot justify moral or political norms on that basis, according to Brennan.

\section{Good News and Bad News}

These conclusions have a variety of positive upshots.

Here's one: the extent to which voters are misinformed is overstated. Although a large number of people will say that Obama is the antichrist, that he founded ISIS, and so forth, many of these people do not genuinely believe these things. Our worries about voter incompetence have been driven not by voter misperceptions but rather by our misperceptions about voters. This is reassuring. A person's willingness to occasionally disregard factual information is far less pernicious than being misinformed, since genuinely believing incorrect information would preclude doubt and obstruct the attainment of truth.

I do not deny that voters are often ignorant. ${ }^{23}$ One of the best-established findings from decades of research in political theory is the extent to which ordinary citizens are ignorant of politics. ${ }^{24}$ Indeed, the studies on expressive responding by Bullock and his colleagues reveal that people will often admit their ignorance on many factual political questions. But this, too, is reassuring. When partisans are motivated to give accurate responses, they display the capacity to acknowledge their own ignorance. ${ }^{25}$ The problem is that people are unwilling to admit their lack of knowledge under ordinary survey conditions.

\footnotetext{
${ }^{23}$ It is common to distinguish ignorance (a lack of information) from misinformation (false or inaccurate information.). When the public is misinformed, then tend to confidently hold false beliefs. As a result, misinformation is often a greater obstacle to educating people with facts.

${ }^{24}$ For surveys, see Delli Carpini and Keeter (1996) and Somin (2013).

${ }^{25}$ Interestingly, there may still be a failure of self-knowledge, since many partisans claim that they "almost never" agree with the other party's position (Doherty et al. 2016). Thus, we may often think that we disagree even when we are not.
} 
In addition to overstating the actual amount of factual disagreement in politics (and the extent to which voters are misinformed), survey responses also tend to exaggerate the degree to which partisanship biases or distorts our perception of the facts. As mentioned earlier, the theory of "motivated reasoning" assumes that the misinformation documented by survey researchers accurately reflects what voters truly believe. But this is an inadequate diagnosis in many cases. It turns out that citizens have the capacity to perceive reality in a less partisan way than many have claimed. This may be good news for democracy. If there were genuine disagreement over basic factual issues, then the possibility of democratic deliberation and compromise would be slim. ${ }^{26}$

In short, people might not be as dumb or as biased as is commonly assumed. What appears to be stupidity or irrationality is often just cheerleading.

Now for the bad news.

An unfortunate consequence of identity-based polarization is that we often cannot resolve partisan conflict by reasoned debate or educating people about the issues. If Mason is right that Democrats and Republicans are affectively polarized despite their agreement on many issues, then attempting to resolve political disagreement by closing partisan gaps on policy issues is misguided. This is a problem for deliberative conceptions of democracy. If our disagreements are not based on genuine reasons or arguments, then we cannot engage with each other's views. This is inconsistent with the idea that citizens should deliberate with each other via rigorous, careful, and open-minded discussion of the issues.

An even larger worry is that the facts don't seem to matter. Individuals do not generally choose to support a political party on the grounds that it best represents their interests,

\footnotetext{
${ }^{26}$ However, it is not clear what hope there is for deliberative democracy if 'political realism' is true and people rarely have genuine political beliefs.
} 
preferences, or values. Quite the opposite. Partisans will edit their list of reasons for holding particular attitudes in order to defend the position that is faithful to their party. Thus, the typical voter's political "views" have little intellectual value. As Somin (2013), Achen and Bartels (2016), Mason (2018), Anderson (in this volume), Brennan (in this volume), and many others have argued, our political identities are only loosely based on our own interests and issue positions. We are happy to cheerlead and protect our group's status as if we had the facts, but the facts do not play a substantive role in shaping our political attitudes or beliefs.

It also follows that we're not really interested in genuinely engaging with the other side. When policy debates are just battles between "us" vs. "them", we no longer select policies based on their actual content and we lose all motivation to reach a compromise. Consider what happened with the Affordable Care Act. When constructing the Act, Democrats incorporated Republican ideas in hopes of winning bipartisan support, but they received none. For Republicans, it wasn't about policy. It was about denying their opponents a win and giving themselves a campaign issue. A compromise would have been seen as an unnecessary concession to "the enemy".

This has implications for policymaking. If the political divide cannot be bridged by creative new policies that incorporate ideas from both the left and right, there is little possibility for bipartisan lawmaking. Policy becomes about one side getting its agenda through and scoring a victory. Instead of constructing bipartisan policies, then, it seems we must try to reduce partisan antipathy by reducing the strength or alignment of political identities.

Partisan cheerleading also corrupts public discourse. When empirical language is appropriated to make expressive claims, it generates confusion about what people are actually saying. As Anderson (in this volume) puts it, "populist political discourse hijacks empirical discourse - the grammar of assertion — for expressive purposes, overtaking spaces normally 
reserved for empirical policy discussion." This harms public discourse by infecting the public domain with misleading information, thereby corrupting human knowledge.

This, too, has policy implications. When we mistakenly interpret expressive discourse literally, we tend to reply with empirical arguments. For instance, if liberal democrats interpret vehement denials of anthropogenic climate change as out of touch with reality, they will criticize their opponents for not engaging with the evidence. This may further antagonize the other side because their opponents will interpret liberals as calling them stupid.

I'll end this section by mentioning a rather strange upshot of my argument. I have argued that politics is characterized by less disagreement than we thought. On this basis, one might conclude that politics has more agreement than we thought. But this does not follow. Indeed, my argument may explain away genuine agreement just as easily as it explains away genuine disagreement. ${ }^{27}$ For example, two people who claim to be pro-regulation may not actually have any settled beliefs on this matter; they may simply make this claim to express partisan support. In general, whenever two people seem to agree on some political issue, they may be expressing similar pro-attitudes without any corresponding beliefs on the matter. Thus, my central claim that there are fewer political disagreements than we thought does not imply that there is more agreement in politics. ${ }^{28}$ We now have to be unsure about whether people who seem to agree are actually agreeing or just cheering for the same side.

\section{Concluding Remarks}

Ballantyne (2016: 759) makes a similar point in the context of verbal disputes in philosophy.

${ }^{28}$ That said, Mason (2018) says there is more issue-based agreement than surveys typically suggest. 
I have no solutions to these problems. ${ }^{29}$ The aim of this paper is not to recommend solutions but rather to change how we look at the problem of political disagreement. In our polarized climate, it is easy (and common) to conclude that politics is rife with disagreement, including factual disagreement. This is allegedly supported by a wealth of survey data. I have argued, however, that many political disagreements are not really disagreements. What appears to be disagreement is often cheap talk and partisan cheerleading.

I have also explored the implications of this idea. As we've seen, the very factors that explain why political disagreement is superficial also explain why debates often go so poorly, why it is difficult to correct false beliefs, and why people seem to hold blatantly contradictory views. The expressive nature of political engagement also raises doubts about standard survey research, the theory of motivated reasoning, and the view that political disagreements are "deep disagreements". The news is not all bad, though. As I've argued, political surveys tend to overstate the level of political misinformation, motivated reasoning is not distorting our perceptions of reality as often as scholars have claimed, and there is less disagreement over the facts than we thought. Ultimately, I hope to have highlighted the importance of thinking carefully about the concept of "disagreement" for future research in politics.

\section{Acknowledgements.}

Thanks to Jeroen de Ridder, Elizabeth Edenberg, Adam Gibbons, Neil Levy, and Robert Ross for comments on an earlier draft.

\footnotetext{
${ }^{2}$ Several solutions have been proposed. For example, correcting misperceptions about party supporters tends to reduce animus toward the other side (Ahler and Sood 2018). Mason (2018) suggests that partisan news media should be compelled to present opposing partisans in more sympathetic ways. We may also try to shift the salience of partisan identities. In general, it seems the only way to reduce partisan antipathy is by reducing the strength of political identities. Thus, another upshot is that we should aim to depoliticize issues as much as possible, since partisan cheerleading trivializes important matters. Talisse (2019) suggests that we should be less politically engaged, since talking to each other about politics tends to activate our political identities. The better thing to do is engage in non-political activities with members of the opposing side.
} 


\section{References}

Abramowitz, A.I. and K. Saunders. 2008. “Is Polarization a Myth?” The Journal of Politics 70 (2): 542-555.

Achen, C. and L. Bartels. 2016. Democracy for Realists. Princeton University Press.

Aikin, S. 2019. "Deep Disagreement, the Dark Enlightenment, and the Rhetoric of the Red Pill.” Journal of Applied Philosophy 36 (3): 420-35.

Ahler, D. and G. Sood. 2018. "The Parties in Our Heads: Misperceptions about Party Composition and Their Consequences." The Journal of Politics 80 (3): 964-981.

Ancell, A. 2019a. "Political Irrationality, Utopianism, and Democratic Theory." Politics, Philosophy and Economics. DOI: 10.1177/1470594x19889108

Ancell, A. 2019b. "The Fact of Unreasonable Pluralism." Journal of the American Philosophical Association 5 (4): 410-428.

Anderson, E. 2021. "Epistemic Bubbles and Authoritarian Politics.” In E. Edenberg and M. Hannon (eds.), Political Epistemology. Oxford University Press.

Arceneaux, K. and M. Johnson. 2013. Changing Minds or Changing Channels? University of Chicago Press.

Ballantyne, N. 2016. "Verbal Disagreements and Philosophical Skepticism." Australasian Journal of Philosophy 94 (4): 752-765. 
Bartels, L. M. 2002. "Beyond the Running Tally: Partisan Bias in Political Perceptions.” Political Behavior 24: 117-50.

Bloom, P. 2016. Against Empathy: The Case for Rational Compassion. Ecco.

Brennan, J. 2021. “Does Public Reason Liberalism Rest on a Mistake? Democracy’s Doxastic and Epistemic Problems.” In E. Edenberg and M. Hannon (eds.), Political Epistemology. Oxford University Press.

Brennan, J. 2017. Against Democracy. Princeton University Press.

Boxell L., M. Gentzkow, and J. M. Shapiro. 2017. “Greater internet use is not associated with faster growth in political polarization among US demographic groups.” PNAS 114 (40): 10612-17.

Bullock, J., A. Gerber, S. Hill and G. Huber. 2015. "Partisan Bias in Factual Beliefs about Politics." Quarterly Journal of Political Science 10 (4): 519-578.

Bullock, J. and G. Lenz. 2019. "Partisan Bias in Surveys." Annual Review of Political Science 22: 325-342.

Campbell, A., Converse, P. E., Miller, W. E., and Stokes, D. E. 1960. The American Voter. Wiley.

Cohen, G. 2003. "Party Over Policy: The Dominating Impact of Group Influence on Political Beliefs.” Journal of Personality and Social Psychology 85: 808-22.

Converse, P. E. 1964. “The Nature of Belief Systems in Mass Publics.” In D. E. Apter (ed.), Ideology and Discontent. The Free Press. 
Delli Carpini, X.M., and S. Keeter. 1996. What Americans Know About Politics and Why It Matters. Yale University Press.

de Ridder, J. 2021. "Deep Disagreement and Political Polarization.” In E. Edenberg and M. Hannon (eds.), Political Epistemology. Oxford University Press.

Doherty, C. J. Kiley, and B. Jameson. 2016. "Partisanship and Political Animosity in 2016." Pew Research Center report. Accessed at: https://www.peoplepress.org/2016/06/22/partisanship-and-political-animosity-in-2016/

Dunning, D. 2017. "We Are All Confident Idiots.” Pacific Standard. Accessed at: https://psmag.com/social-justice/confident-idiots-92793.

Fernbach, P. M., Rogers, T., Fox, C. R., and Sloman, S. A. 2013. "Political Extremism Is Supported by an Illusion of Understanding." Psychological Science 24 (6): 939-946.

Fiorina, M. P., Abrams, S. J., Pope, J. C. 2008b. "Polarization in the American Public: Misconceptions and Misreadings.” The Journal of Politics 70: 556-560.

Greenstein, F. 1965. Children and Politics. Yale University Press.

Haidt, J. 2012. The Righteous Mind. Random House.

Huber G.A. and O. Yair. 2018. "How Robust Is Evidence of Perceptual Partisan Bias in Survey Responses? A New Approach for Studying Expressive Responding." Presented at the Midwest Political Science Association Annual Meeting, Apr. 5-8, Chicago, IL.

Huemer, M. 2016. “Why People Are Irrational About Politics.” In J. Anomaly et al. (eds.), Philosophy, Politics, and Economics: An Anthology. Oxford University Press. 
Iyengar, S., G. Sood, and Y. Lelkes 2012. “Affect, Not Ideology: A Social Identity Perspective on Polarization." Public Opinion Quarterly 76: 405-31.

Jacobson G. C. 2010. "Perception, Memory, and Partisan Polarization on the Iraq War." Political Science Quarterly 125: 31-56.

Jennings, M. and Niemi, R. 1981. Generations and Politics: A Panel Study of Young Adults and Their Parents. Princeton University Press.

Jerit, J. and J. Barabas. 2012. "Partisan Perceptual Bias and the Information Environment." The Journal of Politics 74: 672-84.

Kappel, K. 2018. “There Is No Middle Ground for Deep Disagreements about Facts.” Aeon Magazine. Accessed at: https://aeon.co/ideas/there-is-no-middle-ground-for-deepdisagreements-about-facts

Khanna, K. and G. Sood. 2018. "Motivated Responding in Studies of Factual Learning." Political Behavior 40 (1): 79-101.

Kinder, D. and N. Kalmoe. 2017. Neither Liberal nor Conservative: Ideological Innocence in the American Public. University of Chicago.

Kull, S., C. Ramsay, S. Subias, and E. Lewis. 2004. "The Separate Realities of Bush and Kerry Supporters.” Program on International Policy Attitudes.

Lelkes, Y., Sood, G., and Iyengar, S. 2017. “The Hostile Audience: Selective Exposure to Partisan Sources and Affective Polarization." American Journal of Political Science 61 (1): $5-20$.

Lenz, G. 2012. Follow the Leader? University of Chicago. 
Levendusky, M. 2013. How Partisan Media Polarize America. University of Chicago Press.

Luskin, R. C., Sood, G., and Blank, J. 2013. "The Waters of Casablanca: Political Misinformation (and Knowledge and Ignorance).” Unpublished manuscript.

Lynch, M. 2019. Know-It-All Society. Liveright.

Mason, L. 2018. Uncivil Agreement: How Politics Became Our Identity. University of Chicago.

Mason, L. 2015. “I Disrespectfully Agree: The Differential Effects of Partisan Sorting on Social and Issue Polarization.” American Journal of Political Science 59: 128-145.

Mason, L. 2013. “The Rise of Uncivil Agreement: Issue Versus Behavioral Polarization in the American Electorate." American Behavioral Scientist 57 (1): 140-159.

Nyhan, B. and Reifler, J. 2010. "When Corrections Fail: The Persistence of Political Misperceptions” Political Behavior 32: 303-330.

Peterson, E. and Iyengar, S. Forthcoming. "Partisan Gaps in Political Information and Information-Seeking Behavior: Motivated Reasoning or Cheerleading?” American Journal of Political Science.

Pew Research Center. 2014. "Political Polarization in the American Public.” Accessed at: https://www.people-press.org/2014/06/12/political-polarization-in-the-american-public/.

Prior, M. 2013. "Media and Political Polarization.” Annual Review of Political Science 16: $101-27$. 
Prior, M. G. Sood and K. Khanna. 2015. "You Cannot be Serious: The Impact of Accuracy Incentives on Partisan Bias in Reports of Economic Perceptions." Quarterly Journal of Political Science 10 (4): 489-518.

Rawls, J. 1993. Political Liberalism. Columbia University Press.

Schaffner, B., S. Luks. 2018. "Misinformation or Expressive Responding? What an Inauguration Crowd Can Tell Us about the source of Political Misinformation in Surveys.” Public Opinion Quarterly 82 (1): 135-147.

Shapiro, R. Y. and Y. Bloch-Elkon. 2008. "Do the Facts Speak for Themselves? Partisan Disagreement as a Challenge to Democratic Competence.” Critical Review 20 (1): 115-39.

Sears, D. 1983. “The Persistence of Early Political Dispositions: The Roles of Attitude Object and Life Stage.” In L. Weaver and P. Shaver (eds.), Review of Personality and Social Psychology. Sage Publications.

Sinnott-Armstrong, W. 2018. Think Again. Penguin.

Somin, I. 2013. Democracy and Political Ignorance. Stanford Law Books.

Taber, C. S. and Lodge, M. 2006. "Motivated Skepticism in the Evaluation of Political Beliefs." American Journal of Political Science 50: 755-769.

Talisse, R. 2019. Overdoing Democracy. Oxford University Press. 